\title{
Prediction of mesothelioma, lung cancer, and asbestosis in former Wittenoom asbestos workers
}

\author{
G Berry
}

\begin{abstract}
Projections have been made of the number of mesotheliomas, lung cancers, and cases of asbestosis that might occur over the period 1987 to 2020 in former workers at the Wittenoom crocidolite asbestos mine in Western Australia. Predictions were based on the observed mortality to the end of 1986 and modelling of the mesothelioma rate. Elimination of crocidolite from the lungs was included in the model. Between the years 1987 and 2020 it is predicted that between 250 and 680 deaths will occur due to mesothelioma. This wide range is due to uncertainty on the functional form of the relation between mesothelioma rate and time, and insufficient data to estimate the elimination rate of crocidolite from the lungs. The most likely range is the lower half of this total range-that is, between 250 and 500 . It is predicted that between 340 and 465 deaths will occur due to lung cancer. About $45 \%$ of these deaths would be attributable to exposure to asbestos. It is estimated that currently there are up to 200 cases of undiagnosed asbestosis. Of these about 50 will die of lung cancer or mesothelioma and are therefore also included in the figures above. Up to 60 former workers may develop the first signs of asbestosis in the future but any such cases are likely to progress to more serious disease at a much slower rate than the cases that have already been identified.
\end{abstract}

The group of former workers employed in the production of crocidolite asbestos at Wittenoom between 1943 and 1966 has been studied by Hobbs $e t$ $a l^{1}$ over the past decade. Out of a workforce of over 6500 men and 400 women there had been 820 deaths in men by the end of $1980,{ }^{2}$ including 32 deaths due to mesothelioma, 91 (standardised mortality ratio (SMR) between 1.6 and 2.6 ) due to cancer of the trachea, bronchus, and lung, and 34 due to pneumoconiosis. de Klerk et al $^{3}$ extended the follow

Department of Public Health, University of Sydney, New South Wales, 2006, Australia G Berry up to the end of 1986 , by which time there had been 94 cases of mesothelioma, 141 cases of lung cancer, and 356 successful compensation claims for asbestosis. The data were used to predict future incidence of these three asbestos related diseases for the period 1987 to 2020 . They predicted 2898 deaths in this period, 692 cases of mesothelioma, 183 cases of lung cancer, and 482 cases of asbestosis. In the present paper an independent set of predictions is reported and compared with those of de Klerk et al. ${ }^{3}$

The characteristics of the workforce have been reported. ${ }^{2}$ Briefly about $45 \%$ of the men had worked at Wittenoom for less than three months and less than $3 \%$ had stayed for more than five years. Fibre concentrations in the mill were high but because of the short exposures most men $(56 \%)$ accumulated less than 10 fibre-years $/ \mathrm{ml}$ and less than $5 \%$ more than 100 fibre-years $/ \mathrm{ml}$. About $80 \%$ of men were known to have worked in the mine, or mill, or both and $62 \%$ started work after 1957 , the year in which a new mill was opened. The women's exposure differed from that of the men since very few worked in the mine or mill and consequently about $90 \%$ had a cumulative exposure of less than 10 fibre-years $/ \mathrm{ml}$.

\section{Methods}

THE POPULATION

Details of the population were supplied by the Perth investigators; the information consisted of sex, year of birth, year and age when they started work at Wittenoom, total days worked, workplace, and average intensity of exposure (fibres/ml) to asbestos. For those who had died the year of death was given and if a mesothelioma or lung cancer had been diagnosed the year of such diagnosis was supplied. For a person known to have emigrated the year of emigration was stated. This information was supplied for 6501 men and 410 women. This data set forms the basis of the predictions described. Cumulative exposure (fibres-year $/ \mathrm{ml}$ ) was calculated as the product of total days worked and average intensity of exposure divided by 365 . As noted by Rogers $^{4}$ the absolute values of fibre concentration are underestimates, but they serve as a means of ranking the different jobs within the Wittenoom population.

Deaths had been recorded for 1176 men and 31 women, and 153 men and six women were recorded 
as having emigrated. This left 5172 men and 373 women as the maximum numbers still alive on 1 January 1987.

A problem that occurs in the follow up of a group such as this in Australia is the difficulty of obtaining positive confirmation that a given subject is still alive after checks of death registries in all the States have failed to identify that the subject has died. Confirmation of vital status had been sought by the checking of electoral rolls, telephone directories, and other sources, ${ }^{2}$ but the vital status was unconfirmed for about a third of the men and almost half of the women on 31 December $1986 .^{3}$ It is reasonable to suppose that most of these subjects would be alive at the end of 1986 as the death of any subject would increase the probability of a confirmed vital status; this would be even more so for a subject dying of mesothelioma or lung cancer since such subjects would be included in state cancer registries. Nevertheless, it is also reasonable to suppose that some deaths would be missed in the search and internal evidence in the data indicates that this has occurred. One piece of such evidence is the excess of men who, if still alive, would have been aged 90 or more at the end of 1986; there were 24 such men, including eight aged over 95 and two over 100 . Only 62 men in the entire group born in 1896 or earlier could have reached the age of 90 , including 22 and eight who could have reached the ages of 95 and 100 respectively. It should be noted that these apparently very old survivors would not have invalidated any of the mortality analyses published by the Perth group as these analyses only included subjects up to the age of 85. A second and more important piece of evidence of undetected deaths came to light in the analysis of mortality reported below.

\section{MORTALITY ANALYSIS}

An analysis of mortality was carried out for the men to establish the amount of excess mortality for all causes of death, lung cancer, and mesothelioma, and the factors of the working environment at Wittenoom that influenced the mortality. In this analysis the first 10 years after first employment at Wittenoom were ignored. Expected deaths for all causes and cancer of the lung were calculated using sex and calendar period specific death rates for Western Australia (these rates were the same as used by the Perth group), the subject-years method, ${ }^{56}$ and a specific computer program. ${ }^{7}$ Associations between excess mortality and features of exposure were analysed using Poisson modelling of the results of the subjectyears analysis. ${ }^{6}$ Mesothelioma mortality was expressed as a rate per 100000 person-years and analysed by Poisson modelling.

\section{MESOTHELIOMA AND DURATION OF FOLLOW UP}

The relation between mesothelioma rate and time since first exposure has been investigated in a number 3 of follow up studies similar to the Wittenoom study. ? It has generally been found that the mesothelioma $\vec{F}$ rate increases according to time since first exposure $(t)$ raised to a power-that is:

$$
\text { rate }=\mathrm{c} \mathrm{t}^{\mathrm{k}}
$$

where the power $k$ would be between 3 and 4 , and the constant $\mathrm{c}$ is dependent on exposure. This formulation does not include any lag period during which mesotheliomas could not occur and lead to death. An alternative that includes such a lag period $\mathrm{w}$ is:

$$
\text { rate }=c(t-w)^{k}
$$

where the power $\mathrm{k}$ would be lower the greater the lag period.

\section{PREDICTION METHOD}

The mortality of the population of men assumed alive on 1 January 1987 was projected forward annually to 31 December 2020. The assumptions in this projection were:

(1) that the death rates for all causes of death would be the rates for Western Australia for 1979 to 1982 , except as modified to take account of the excess deaths from lung cancer and mesothelioma in (2) and (3) below. An exponen tial equation in age was fitted to the rates for a causes.

(2) That the death rates due to lung cancef would be those for Western Australia multi: plied by a factor representing the excess associated with exposure to crocidolite at Wittenoom. This factor, the SMR, depended on cumulative exposure to asbestos at Wittenoom. (3) That the mesothelioma death rate would be modelled according to time since first exposure, and would also contain a factor dependent on cumulative exposure.

These death rates were applied to the assumed population alive on 1 January of each year and the number of deaths expected during the year were calculated (assuming that deaths would occur uniformly throughout the year). This calculation gave the number of survivors at the end of the year and this was the starting population for the next year's calculation.

Three different models of mesothelioma rate were fitted, for lag times of zero, five, and 10 years. Also, some modified models were used. In one of these the background death rates due to lung cancer were assumed to decline at $2 \%$ per calendar year because of a decline in smoking. In another, increase in mesothelioma rate with time since exposure was moderated by a factor representing a decline in risk to correspond to elimination of asbestos from the lungs. This model was:

$$
\text { rate }=c e^{-\lambda t}(t-w)^{k}
$$


Table 1 Mortality analysis

\begin{tabular}{|c|c|c|c|c|}
\hline Cause of death & Observed & Expected & Ratio & Rate per $10^{5} \mathrm{my}$ \\
\hline $\begin{array}{l}\text { All ages: } \\
\text { All causes } \\
\text { Lung cancer } \\
\text { Mesothelioma }\end{array}$ & $\begin{array}{r}983 \\
122 \\
84\end{array}$ & $\begin{array}{r}1114 \cdot 0 \\
88.1 \\
-\quad\end{array}$ & $\begin{array}{l}0.88 \\
1.38 \\
-\end{array}$ & 81 \\
\hline $\begin{array}{l}\text { Ages up to } 65: \\
\text { All causes } \\
\text { Lung cancer } \\
\text { Mesothelioma }\end{array}$ & $\begin{array}{r}719 \\
87 \\
72\end{array}$ & $\begin{array}{r}601.8 \\
48.7 \\
-\quad\end{array}$ & $\begin{array}{l}1 \cdot 19 \\
1.79 \\
-\end{array}$ & 76 \\
\hline $\begin{array}{l}\text { Ages of } 65 \text { and old } \\
\text { All causes } \\
\text { Lung cancer } \\
\text { Mesothelioma }\end{array}$ & $\begin{array}{r}\text { er: } \\
264 \\
35 \\
12\end{array}$ & $\begin{array}{r}512.2 \\
39.4 \\
-\quad\end{array}$ & $\begin{array}{l}0.52 \\
0.89 \\
-\end{array}$ & 136 \\
\hline
\end{tabular}

\section{Results of mortality analysis}

In 6258 men followed up for more than 10 years there had been 983 recorded deaths, of which 122 were due to lung cancer and 84 to mesothelioma. Table 1 presents the subject-years analysis in which the follow up has been subdivided into ages up to 65 and 65 and older. In spite of the excess mortality due to lung cancer overall, this analysis showed an apparent deficit of deaths due to all causes and to lung cancer but not to mesothelioma, at ages of 65 or older. A more detailed tabulation showed that the apparent deficit increases with increasing age beyond 65 . The most reasonable explanation is that undetected deaths occurred. The results of de Klerk et al ${ }^{3}$ (see their fig 4), in which the increase in death rate beyond age 65 was less than expected, support this interpretation. To compensate for this two things have been done. Firstly, in the analysis to determine the environmental factors influencing mortality only mortality experience up to age 65 has been included. Secondly, the population alive on 1 January 1987, which was used for prediction, has been adjusted.

It should be noted that the excess mortality from all causes up to age 65 ( 117 deaths) is almost equal to the excess number of lung cancer deaths (38) and the number of mesotheliomas (72).

As expected from the earlier work ${ }^{23}$ the excess mortality from lung cancer and from mesothelioma both increased with increasing time worked at Wittenoom, and with increasing cumulative exposure. The excesses were also greater for those who had worked in the mill and for those who were first employed before 1957. The excess rate of lung cancer was relatively stable with increasing duration of follow up beyond 10 years, but the mesothelioma rate increased rapidly with duration of follow up.

The exposure factors above were associated. For example, the group was divided into those first employed before 1957 and later because an improvement in conditions was reported at that time. This improvement is reflected in the intensity of exposure, and hence in the measure of cumulative

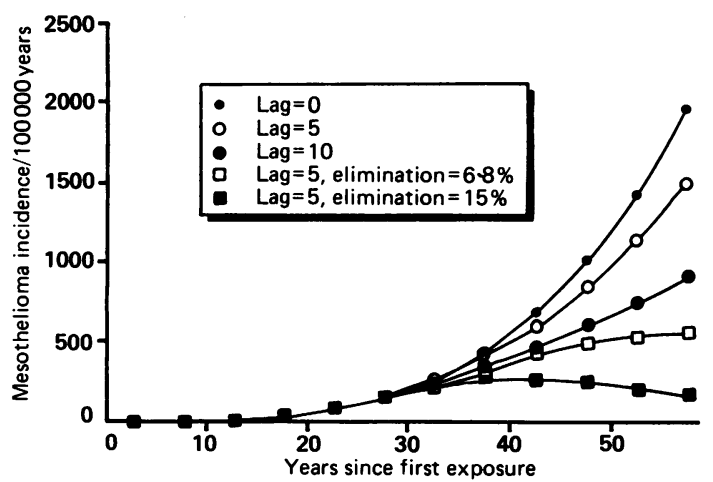

Figure 1 Fitted mesothelioma rates for lag periods of zero, 5 , and 10 years, and for models with elimination of crocidolite from lungs.

exposure. Similarly, differences between the mine and mill will be incorporated into cumulative exposure, which by definition is also associated with duration of exposure. The consequence of these associations was that the excess mortality could be modelled using only cumulative exposure as a measure of the working environment, and also taking account of duration of follow up for mesothelioma.

\section{MESOTHELIOMA AND DURATION OF FOLLOW UP}

The relation between mesothelioma death rate and time since first exposure used was:

$$
\text { rate }=c(t-w)^{k}
$$

with lag periods $w$ of zero, five, and 10 years considered. The constant $c$ was related to the cumulative exposure. It was found that the observed time pattern of mesothelioma deaths was fitted almost equally well by the three models with estimates of the power $k$ of $3.52,2.71$, and 1.80 for lags of zero, five, and 10 years respectively.

If the only purpose of an analysis were to explain the mortality already observed the model with zero lag period would be favoured on the grounds of parsimony-that is, the model contains fewer parameters. When the purpose, however, is to predict future mortality involving extrapolation to durations of follow up not yet observed, the distinction is critical. Although a range of values of lag period give similar mesothelioma rates within the range of the data these rates diverge appreciably thereafter. This is illustrated in fig 1 , in which the fitted mesothelioma rate, averaged over exposure, is plotted against time since first exposure for lag periods of zero, five, and 10 years. The agreement between these three models up to 35 years from first exposure, which covers most of the observed follow up, is clear. Between 30 and 35 years from first exposure the mesothelioma rate is about 250 per 100000 person-years. The divergence thereafter is 
Table 2 Age distribution of men surviving on 1 January 1987

\begin{tabular}{lcc}
\hline Age group & Maximum survivors & Assumed survivors \\
\hline $34-39$ & 90 & 90 \\
$40-44$ & 597 & 597 \\
$45-49$ & 1105 & 1105 \\
$50-54$ & 901 & 901 \\
$55-59$ & 976 & 976 \\
$60-64$ & 643 & 643 \\
$65-69$ & 356 & 320 \\
$70-74$ & 221 & 177 \\
$75-79$ & 133 & 93 \\
$80-84$ & 83 & 50 \\
$85-89$ & 43 & 22 \\
$90-94$ & 16 & 6 \\
$\geqslant 95$ & 8 & 2 \\
Total & 5172 & 4982 \\
\hline
\end{tabular}

striking and is twofold after 55 years, a duration of follow up that all former workers will reach by 2020 . The rate reaches 1400,1100 , and 700 per 100000 person-years by 50 to 55 years since first exposure for the models with lag zero, five, and 10 years respectively. Figure 1 also shows the fitted mesothelioma rates after fitting two models with elimination, rate = $\mathrm{ce}^{-i t}(t-w)^{k}$. For a lag of five years, the maximum likelihood estimate of $\lambda$ was 0.068 , corresponding to elimination of $6.8 \%$ per year, with $k$ as 3.92 . With this model the mesothelioma rate is relatively constant after 40 years since first exposure and reaches 525 per 100000 person-years by 50 to 55 years. This estimate of $\lambda$ was imprecise and a value of $0 \cdot 15$, with $k$ $=5 \cdot 4$, fitted the data almost as well, giving a peak rate between 40 and 45 years since first exposure of 265 per 100000 person-years followed by a decline to 210 per 100000 person-years by 50 to 55 years.

\section{POPULATION OF MEN ALIVE ON 1 JANUARY 1987}

A maximum of 5172 men survived to 1 January 1987 , but evidence existed showing that some of these aged 65 or older not recorded as dead were in fact dead, and that the proportion of undetected deaths increased with age. Accordingly the population assumed alive on 1 January 1987 was reduced by $10 \%, 20 \%$, etc to $70 \%$ for those aged 65 to 69,70 to 74 , etc to 95 or older respectively. This gave 4982 men (table 2).

\section{WOMEN}

Only 410 women were in the group and there were only 31 recorded deaths. Two mesotheliomas and three lung cancers have been diagnosed. With these small numbers a detailed mortality analysis would not be informative.

\section{Prediction results \\ MESOTHELIOMA AND LUNG CANCER}

Table 3 gives details of the mortality models used and parameter values.

The first prediction was that no excess lung cance mortality or mesotheliomas occurred. This serves as a baseline as it indicates the mortality that would have been expected if working at Wittenoom had produced no asbestos-related mortality. Table 4

Table 3 Mortality models used for prediction

Western Australia death rates from all causes (DRAC) (men):

DRAC $=\exp (-9.759+0.09348$ *age on January 1$)$

Western Australia death rates from lung cancer (DRLC) (men):

$\mathrm{DRLC}=28,72,310,692,1362,1972,3439,4781,6629,5887,4955$ per million for age groups $35-39,40-44,45-49,50-54,55-59$, $60-64,65-69,70-74,75-79,80-84, \geqslant 85$

SMR for lung cancer due to exposure at Wittenoom (SMRLC):

SMRLC $=1.34$ for cumulative exposure less than 10 fibre-years $/ \mathrm{ml}$

1.78 for cumulative exposure 10 to less than 50 fibre-years $/ \mathrm{ml}$

1.80 for cumulative exposure 50 to less than 100 fibre-years $/ \mathrm{ml}$

5.97 for cumulative exposure 100 or more fibre-years $/ \mathrm{ml}$

1.78 for cumulative exposure unknown

Mesothelioma rate (DMS):

DMS $=\exp [a+b+k \star l n(t-l a g)]$ where for

(1) lag $=0$

$\mathrm{a}=-18.48, \mathrm{k}=3.517$

$\mathrm{b}=0,0.9273,1.150,1.931,-0.6655$ for the five categories of cumulative exposure given above

(2) lag $=5$ years

$\mathrm{a}=-15 \cdot 23, \mathrm{k}=2 \cdot 707$

$\mathrm{b}=0,0.9256,1.146,1.932,-0.6492$ for the five categories of cumulative exposure given above

(3) $\mathrm{lag}=10$ years

$\mathrm{a}=-11.94, \mathrm{k}=1.796$

$\mathrm{b}=0,0.9248,1.142,1.937,-0.6103$ for the five categories of cumulative exposure given above

Total death rate (DTOT):

DTOT $=$ DRAC + (SMRLC -1$) \star D R L C+D M S$

Probability of dying in year $=\mathrm{DTOT} /(1 \cdot 0+0.5 \star \mathrm{DTOT})$ 
Table 4 Predicted mortality with no asbestos related excess

\begin{tabular}{llllll}
\hline & \multicolumn{3}{c}{ All causes } & & \multicolumn{2}{l}{ Lung cancer } \\
\cline { 2 - 3 } \cline { 5 - 6 } Years & Per year & Cumulative & & Per year & Cumulative \\
\hline $1987-90$ & 82 & 327 & 7 & 28 \\
$1991-5$ & 98 & 815 & & 9 & 71 \\
$1996-2000$ & 117 & 1399 & & 10 & 123 \\
$2001-5$ & 134 & 2069 & & 11 & 180 \\
$2006-10$ & 144 & 2787 & & 11 & 235 \\
$2011-5$ & 140 & 3486 & & 9 & 281 \\
$2016-20$ & 120 & 4088 & & 7 & 315
\end{tabular}

Age distribution of deaths to 31 December 2020

\begin{tabular}{llc}
\hline Age & All causes & Lung cancer \\
\hline$\leqslant 49$ & 41 & 2 \\
$50-54$ & 91 & 8 \\
$55-59$ & 194 & 21 \\
$60-64$ & 363 & 36 \\
$65-69$ & 570 & 61 \\
$70-74$ & 779 & 73 \\
$75-79$ & 855 & 71 \\
$80-84$ & 670 & 31 \\
$85-89$ & 379 & 10 \\
$\geqslant 90$ & 146 & 2 \\
\hline
\end{tabular}

gives the details of this prediction. In summary there would have been 4088 deaths in men by the year 2020 and $315(7 \cdot 7 \%)$ of these deaths would have been due to lung cancer. A corresponding approach for women gave 232 deaths, five with lung cancer, out of 356 assumed survivors at the beginning of 1987 .

The next set of predictions were for the models with excess lung cancer mortality and mesothelioma mortality discussed earlier, with allowance made for risk varying with cumulative exposure, and for mesothelioma lag periods of zero, five, and 10 years. Table 5 summarises the results with more details in tables 6 and 7. The numbers of deaths due to all causes and due to lung cancer are only slightly affected by the mesothelioma lag period; a total of about 4300 deaths are expected to occur, which would leave about 700 survivors at the end of 2020 , and about 450 $(10.5 \%)$ of the deaths would be due to lung cancer. The predicted number of deaths due to mesothelioma depends critically on the mesothelioma lag period, $654(15 \cdot 1 \%), 573(13.3 \%)$, and $441(10.4 \%)$ for lags of zero, five, and 10 years respectively. The predicted number of deaths due to mesothelioma also depends critically on the power $\mathrm{k}$ in the equation
Table 6 Predicted mortality due to all causes and lung cancer for mesothelioma model with lag of 5 years

\begin{tabular}{lcclll}
\hline & \multicolumn{2}{l}{ All causes } & & \multicolumn{2}{l}{ Lung cancer } \\
\cline { 2 - 3 } \cline { 5 - 6 } Years & Per year & Cumulative & & Per year & Cumulative \\
\hline $1987-90$ & 98 & 391 & & 12 & 47 \\
$1991-5$ & 115 & 966 & 14 & 117 \\
$1996-2000$ & 134 & 1635 & & 16 & 197 \\
$2001-5$ & 146 & 2366 & & 16 & 277 \\
$2006-10$ & 147 & 3103 & & 15 & 351 \\
$2011-5$ & 134 & 3772 & & 12 & 410 \\
$2016-20$ & 107 & 4304 & & 8 & 449
\end{tabular}

Age distribution of deaths to 31 December 2020

\begin{tabular}{lcc}
\hline Age & All causes & Lung cancer \\
\hline$\leqslant 49$ & 54 & 3 \\
$50-54$ & 121 & 12 \\
$55-59$ & 255 & 32 \\
$60-64$ & 453 & 55 \\
$65-69$ & 674 & 92 \\
$70-74$ & 850 & 105 \\
$75-79$ & 853 & 95 \\
$80-84$ & 608 & 40 \\
$85-89$ & 319 & 12 \\
$\geqslant 90$ & 118 & 3 \\
\hline
\end{tabular}

relating mesothelioma rate and time since exposure. The values of $k$ in table 3 are the maximum likelihood estimates. For a lag period of zero, the $95 \%$ confidence limits for $\mathrm{k}$ were 2.66 and 4.42 . Using these values the number of mesotheliomas predicted by 2020 ranged from 410 to 1007 (394 to 960 aged less than 85 ), whereas with $\mathrm{k}$ set as 3.0 the predicted number was 499 (478 aged less than 85). Another possibility considered was that elimination of asbestos from the lungs occurred and hence a reduction in the parameter $c$ with time since exposure. For a lag of five years, a rate of elimination of $6.8 \%$ per year, and $k$ $=3.92$, the number of predicted mesotheliomas was 383 (tables 5 and 7) compared with 573 without elimination. For a rate of elimination of $15 \%$ per year and $\mathrm{k}=5 \cdot 4$, the number of predicted mesotheliomas was 255.

Figure 2 shows the cumulative number of mesotheliomas for lag periods of zero, five, and 10 years, and for the models with elimination and a lag of five years. Figure 3 shows the average numbers of mesotheliomas per five year period. With a lag of zero the peak incidence is 24 per year between 2001 and 2010; for a lag of five years the peak is 21 between 2001

Table 5 Predicted mortality by 2020 for different models of mesothelioma rate

\begin{tabular}{|c|c|c|c|c|c|c|}
\hline \multirow[b]{2}{*}{$\operatorname{Lag}(y)$} & \multicolumn{3}{|l|}{ All ages } & \multicolumn{3}{|c|}{ Aged less than 85} \\
\hline & All causes & Lung cancer & Mesothelioma & All causes & Lung cancer & Mesothelioma \\
\hline $\begin{array}{c}0 \\
5 \\
10 \\
5, \lambda=0.068 \\
5, \lambda=0.15\end{array}$ & $\begin{array}{l}4332 \\
4304 \\
4261 \\
4239 \\
4198\end{array}$ & $\begin{array}{l}444 \\
449 \\
459 \\
462 \\
473\end{array}$ & $\begin{array}{l}654 \\
573 \\
441 \\
383 \\
255\end{array}$ & $\begin{array}{l}3904 \\
3867 \\
3810 \\
3782 \\
3728\end{array}$ & $\begin{array}{l}430 \\
434 \\
443 \\
447 \\
456\end{array}$ & $\begin{array}{l}624 \\
548 \\
425 \\
372 \\
250\end{array}$ \\
\hline
\end{tabular}


Table 7 Predicted mortality for mesothelioma for models with lag of zero, 5, and 10 years, and for models with elimination of dust from lungs (lag 5 years, elimination rates 0.068 and $0 \cdot 15$ )

\begin{tabular}{|c|c|c|c|c|c|c|c|c|c|c|}
\hline \multirow[b]{3}{*}{ Years } & \multicolumn{6}{|c|}{ No elimination } & \multicolumn{4}{|c|}{ Lag = five years with elimination } \\
\hline & \multicolumn{2}{|l|}{ Lag $=0$} & \multicolumn{2}{|c|}{ Lag $=$ five years } & \multicolumn{2}{|c|}{ Lag $=10$ years } & \multicolumn{2}{|l|}{$\lambda=0.068$} & \multicolumn{2}{|l|}{$\lambda=0 \cdot 15$} \\
\hline & Per year & Cumulative & Per year & Cumulative & Per year & Cumulative & Per year & Cumulative & Peryear & Cumul \\
\hline $\begin{array}{l}1987-90 \\
1991-5 \\
1996-2000 \\
2001-5 \\
2006-10 \\
2011-5 \\
2016-20\end{array}$ & $\begin{array}{l}12 \\
17 \\
21 \\
24 \\
24 \\
21 \\
16\end{array}$ & $\begin{array}{r}49 \\
132 \\
236 \\
354 \\
473 \\
576 \\
654\end{array}$ & $\begin{array}{l}12 \\
16 \\
19 \\
21 \\
20 \\
17 \\
13\end{array}$ & $\begin{array}{r}48 \\
125 \\
220 \\
324 \\
424 \\
510 \\
573\end{array}$ & $\begin{array}{r}11 \\
13 \\
15 \\
16 \\
15 \\
12 \\
8\end{array}$ & $\begin{array}{r}44 \\
111 \\
188 \\
267 \\
340 \\
399 \\
441\end{array}$ & $\begin{array}{r}11 \\
13 \\
14 \\
14 \\
12 \\
9 \\
6\end{array}$ & $\begin{array}{r}44 \\
110 \\
183 \\
252 \\
311 \\
355 \\
383\end{array}$ & $\begin{array}{r}10 \\
11 \\
11 \\
9 \\
6 \\
4 \\
2\end{array}$ & $\begin{array}{r}40 \\
96 \\
150 \\
194 \\
225 \\
245 \\
255\end{array}$ \\
\hline \multicolumn{11}{|c|}{ Age distribution of deaths to 31 December 2020} \\
\hline \multirow[b]{2}{*}{ Age } & \multirow{2}{*}{\multicolumn{2}{|c|}{$\operatorname{Lag}=0$}} & \multirow{2}{*}{\multicolumn{2}{|c|}{ Lag $=$ five years }} & \multirow{2}{*}{\multicolumn{2}{|c|}{ Lag $=10$ years }} & \multicolumn{3}{|c|}{ Lag = five years with elimination } & \\
\hline & & & & & & & $\lambda=0.068$ & & $\lambda=0.15$ & \\
\hline $\begin{array}{l}\leqslant 49 \\
50-54 \\
55-59 \\
60-64 \\
65-69 \\
70-74 \\
75-79 \\
80-84 \\
85-89 \\
\geqslant 90\end{array}$ & & $\begin{array}{r}12 \\
27 \\
56 \\
92 \\
124 \\
137 \\
113 \\
63 \\
24 \\
6\end{array}$ & & $\begin{array}{l}12 \\
27 \\
53 \\
84 \\
09 \\
17 \\
94 \\
52 \\
20 \\
5\end{array}$ & $\begin{array}{r}12 \\
25 \\
46 \\
69 \\
84 \\
85 \\
67 \\
36 \\
14 \\
3\end{array}$ & & $\begin{array}{r}13 \\
26 \\
46 \\
66 \\
75 \\
70 \\
51 \\
26 \\
9 \\
2\end{array}$ & & $\begin{array}{r}13 \\
24 \\
39 \\
49 \\
49 \\
40 \\
25 \\
11 \\
4 \\
1\end{array}$ & \\
\hline
\end{tabular}

and 2005, for a lag of 10 years the peak is 16 between 2001 and 2005. For the model with an elimination rate of $6.8 \%$ the peak of 14 occurs between 1996 and 2000 , and for an elimination rate of $15 \%$ the peak of 11 per year is predicted to occur between 1991 and 1995.

Smoking rates in men have been declining in recent years and it is reasonable to suppose that this will result in a decline in lung cancer rates in the future. Accordingly models were used for prediction in which the lung cancer rates at all ages in the general population declined at $2 \%$ per year; this is equivalent to a halving of the rates over 34 years. The asbestos

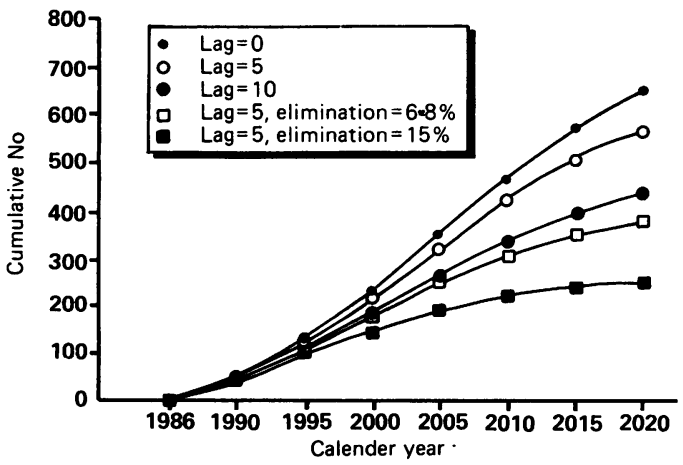

Figure 2 Cumulative number of predicted mesotheliomas for lag periods of zero, 5 , and 10 years, and for models with elimination of crocidolite from lungs. related mesothelioma rates and SMRs for excess lung $\varnothing \vec{\emptyset}$ cancer were taken as above. The predicted number of lung cancers was reduced to $336(7.9 \%)$ with a reduction of about 40 deaths overall and an increase $\rightleftharpoons$ of about 10 deaths due to mesothelioma as a consequence of the increased numbers at risk in any year.

ASBESTOSIS

The situation with asbestosis is different from that with mesothelioma and lung cancer. The diagnosis of asbestosis depends not only on the onset of this condition but also on a person seeking medical assessment. It is possible for a person to be undiag-

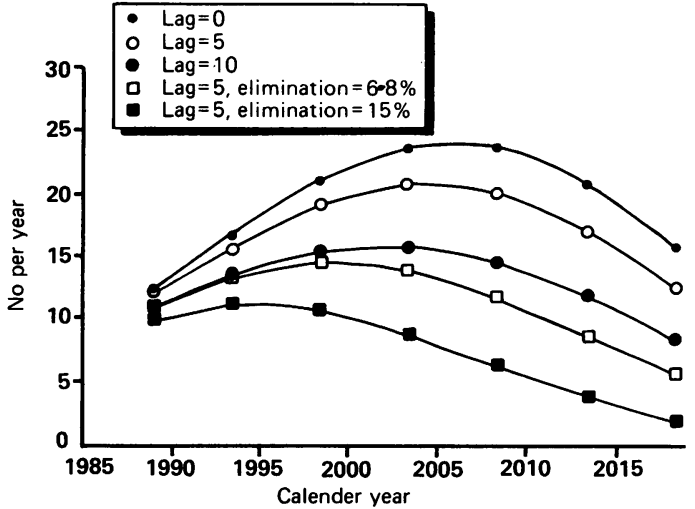

Figure 3 Predicted mesothelioma incidence per year for lag periods of zero, 5 , and 10 years, and for models with elimination of crocidolite from lungs. 
nosed for several years after the disease has reached a stage where it could be diagnosed. Also, whereas the mortality of persons with asbestosis is higher because of the disease, persons with the disease could live for many years and eventually die of some other cause. A further complication is that the criteria for diagnosis are not invariant over time.

There were 356 successful asbestosis claims to the Pneumoconiosis Board by the end of $1986 .{ }^{3}$ One hundred of these claims were successful between 1981 and 1986, and the numbers in each of these six years were $12,8,6,14,41$ and 19 . The high number in 1985 was thought to be due to "the need . . . to apply for compensation before a certain legislated date," as well as the other factors mentioned earlier.

Up to the end of 198641 deaths had occurred for which the cause of death was recorded as asbestosis. Of the $\mathbf{3 5 6}$ who had made a successful claim to the Pneumoconiosis Board, 167 had died by the end of $1986 ; 37(22 \%)$ of these deaths were due to asbestosis and, as these are included in the 41 above, only four deaths were attributed to asbestosis in former workers not diagnosed in life. Also, out of the $\mathbf{3 5 6}$ with asbestosis, 40 had been diagnosed with lung cancer and 10 with mesothelioma.

The variation in delay between onset and diagnosis of asbestosis makes it difficult to model the biological process of onset. Walker et $a^{8}$ approached this problem as follows: Firstly, based on published results, they argued that in a group with asbestosis there will be one death due to mesothelioma per year per 200 persons. Not all persons with mesothelioma have asbestosis, however, and they took a figure of $28 \%$ as the proportion of those with mesothelioma who have asbestosis. Applying this argument to the Wittenoom men we have shown an average of 8.7 deaths of mesothelioma a year in 1981-6 (52 deaths in six years). About $2.5(28 \%$ of 8.7$)$ of these cases would come from the group with asbestosis and therefore this group would consist of 500 men. This is an estimate of the number of men with diagnosable asbestosis alive at the beginning of the 1980s. This approach depends on the figure of $28 \%$, which was from a different situation and would not apply exactly to the Wittenoom group.

A second approach adopted by Walker et al ${ }^{8}$ gives an independent estimate. It is based on a rough equality in the numbers of deaths due to mesothelioma and asbestosis, on about $20 \%$ of deaths in a group of asbestotic subjects being recorded as due to asbestosis, and the death rate of those with asbestosis being about three times the expected rate. This argument can be adapted to the Wittenoom group, substituting values from that group. By the end of 1986,84 deaths with mesothelioma and 41 with asbestosis had occurred. Because about 10 mesothelioma deaths occur per year, one may expect about five deaths a year due to asbestosis. As $22 \%$ (37/167 above) of the deaths in asbestotic subjects were due to asbestosis, then five deaths a year from asbestosis would occur in a total of about 23 deaths out of a group with asbestosis. Cookson et al ${ }^{9}$ found that in a group of 354 claimants to the Pneumoconiosis Board for asbestosis, the SMR for all cases of death was $2 \cdot 65$. Because not all of the group had asbestosis (about 276 of the claims were successful) an SMR of 3.0 for those with asbestosis seems reasonable. The current expected death rate in Wittenoom men is about 0.017 per year and multiplying by three gives a rate of about 0.05 in those with asbestosis at the beginning of the 1980s. Thus to give 23 deaths a year there would have to be about 460 with asbestosis at the beginning of the 1980 s.

The above numbers include those already diagnosed and still alive in 1980 , about 300 , so they indicate between 160 and 200 cases of undiagnosed asbestosis.

\section{Discussion}

The mortality analyses have been carried out using the age specific death rates for Western Australia as an indication of the mortality that would have been expected if the Wittenoom workers had experienced the same mortality as other people of the same sex and age in the state. This is the usual approach in studies of this type and is based on the availability of state death rates. One way that these rates could not be completely appropriate arises from the healthy worker effect-that is, that men who applied for and were accepted for employment at Wittenoom would exclude the chronically ill and so be expected to have a more favourable mortality than the state average. Although this would be the case at the start of employment the healthy worker effect declines over the years as members of the group develop chronic illnesses. Although they may leave the workforce or change jobs because of this they would remain in the study. Mortality was only considered 10 or more years after first employment at Wittenoom and the influence of the healthy worker effect is likely to be small.

\section{MESOTHELIOMA}

The number of mesotheliomas expected by the year 2020 has a range of 441 to 654 men considering only models without elimination of crocidolite from the lungs. The second figure is an extreme result based on the assumption that no lag time occurs for the development of a mesothelioma to the stage of death. This is so unrealistic that, even though such a model fits the existing data, it should be disregarded for predictive purposes. Allowing for a lag period of at least five years reduces the upper limit to 573 mesotheliomas in men.

The predictions make allowance for the duration 
and intensity of exposure and this is important as failure to make such allowance gives predictions higher by $10 \%$. The measure of degree of exposure is clearly not perfect, and if a better measure were available then lower predictions would be obtained. The extent of such a reduction is unknown but crude measures are surprisingly effective in such circumstances, and it is unlikely that any overprediction through the use of a crude exposure measure exceeds $10 \%$. That is, the lower limit would not be less than 400 , again not considering elimination.

About $50 \%$ of the deaths due to mesothelioma would occur before the age of $70,37 \%$ between 70 and 80 , and $13 \%$ at age 80 or older.

These predictions have been based on a frequently used model of the relation between incidence of mesothelioma and time since exposure, in which the incidence is assumed to continue to increase indefinitely according to a power of time, possibly after subtraction of a lag period. For a lag period of zero the estimate of the power obtained was 3.5 , which is in agreement with other studies. ${ }^{1011}$ The decision as to whether to include a non-zero lag period cannot be made from the data as all values from zero to 10 years give a good fit. It would be unreasonable to take the lag period as greater than 10 years because it is generally accepted that a mesothelioma could develop to the point of causing death in that time. As the model with zero lag period here, as usual, fits the data well this model could be preferred on the grounds of parsimony-that is, the model contains fewer parameters. Although this model predicts some mesotheliomas causing death within 10 years, the number is small and not noticeably in conflict with data. It does, however, appear to be in conflict with biology, considerations of which require the passage of some non-zero time for a malignant process to proceed so that the tumour is sufficiently advanced to cause death. These considerations do not lead to an unambiguous estimate of the lag period, however, and values of zero, five, and 10 years have been presented to indicate a range of uncertainty in the predictions. The predictions also depend to a large extent on the power parameter in the relation. Although this was not estimated precisely in this study ( $95 \%$ confidence interval 2.7 to 4.4 ) it is unreasonable to regard this full range as reasonable, as other studies indicate that the power is probably between 3 and 3.5. The last value is the estimate from the Wittenoom data, and predictions were also done using a value of 3 , which gave 499 mesotheliomas.

Whether it is reasonable to suppose that incidence will continue to increase indefinitely for up to 60 years is an open question, as no groups have been followed up for this period. The general question of the role of time in incidence of cancer was reviewed by Thomas. ${ }^{12}$ It was suggested in a follow up of amosite workers in the United States that incidence declined after about 35 years. ${ }^{13}$ Also, the mesothelioma rate was apparently declining in a group of London factory workers, ${ }^{14}$ and the number of mesotheliomas that had occurred in a period of eight years was less than that predicted earlier. ${ }^{15}$ On the other hand such a reduction did not occur in the study of Her Majesty's naval bases in the United Kingdom with a follow up of over 40 years. ${ }^{11}$ Nicholson et al ${ }^{16}$ used a constant risk after 45 years from onset of exposure; the risk of 1200 per 100000 person-years for insulation workers with at least 25 years of employment compares with a range from 250 to 1000 per 100000 person-years for the different models fitted to the Wittenoom group, whose exposure was much shorter. The rate would be expected to decline, or at least to have a reduced rate of increase, if elimination of asbestos from the lungs occurred or if asbestos in the lungs became less carcinogenic with ageing. Although elimination of crocidolite is slow compared with chrysotile some elimination would occur. In rats $73 \%$ of crocidolite was eliminated in 18 months after the cessation of exposure by inhalation. ${ }^{17}$ Berry $e t$ al ${ }^{18}$ postulated that elimination was the explanation for the risk of mesothelioma in exposed groups being higher than the lung contents found many years after the end of exposure would indicate, showing that the lung contents and mesothelioma rates were consistent with an elimination of $15 \%$ per year. The data on mesotheliomas at Wittenoom were insufficient to estimate the rate of elimination precisely, but the best estimate of $6.8 \%$ a year was consistent with the data, as was a higher rate of $15 \%$; these gave much reduced $?$ predicted numbers of mesotheliomas of 383 and 255 respectively.

The problem with the model containing three parameters, $\mathrm{k}, \mathrm{w}$, and $\lambda$, is that with the data available the parameter estimates are highly correlated, and for this reason the best fitting three parameter model did not fit significantly better than the best fitting model with only the parameter $k$ included. Sufficient biological rationale and evidence exists to suggest that the three parameter model is plausible even though the data are currently insufficient to validate it. The consequence of the present uncertainty is that the range of predictions is wide and will only be narrowed as more data accumulate. This is not a surprising conclusion at this stage.

The women had a completely different pattern of exposure to crocidolite than the men. Up to the end of 1986 only two mesotheliomas have been diagnosed in women compared with 94 in men. Based on this proportion, the predicted number of mesotheliomas in women by 2020 would be about 10 to 12 .

\section{LUNG CANCER}

Most of the deaths from lung cancer will occur in men and the predicted total number by 2020 is about 450 based on current background rates and relative risks due to exposure at Wittenoom. Lung cancer rates in men are expected to decline over the next 30 years as a result of a decline in smoking. Assuming a rate of decline of $2 \%$ a year, the predicted number of 
lung cancers would be 336 .

Deaths due to lung cancer would have occurred even if working at Wittenoom had produced no increase in risk. The overall SMR for lung cancer was 1.79 so that about $45 \%$ of deaths from lung cancer would be attributable to exposure to asbestos-that is, about 200 of the predicted 450 . The actual excess, compared with the prediction with no asbestos effect (table 4), is 135 lung cancer deaths but this does not take account of the fact that an increased rate not only results in more cases but also some that would have occurred in any case, occur earlier. These figures are based on the assumption that the Wittenoom workers had similar smoking habits to other men of the same age.

About $43 \%$ of the deaths due to lung cancer would occur before age $70,45 \%$ between 70 and 80 , and $12 \%$ at age 80 or older.

\section{ASBESTOSIS}

The close agreement between the two approaches of predicting the number of former workers with asbestosis not yet detected provides some reassurance that the predictions are reasonable. The agreement is, however, to some extent fortuitous. The first approach involved using factors calculated in different circumstances, but the second approach was self contained. This approach was based on the number of deaths caused by asbestosis being about half the number due to mesothelioma. This was the situation at the end of 1986 (41 asbestosis deaths, 84 mesotheliomas) but at the end of 1980 the numbers were almost equal ( 34 asbestosis, 32 mesotheliomas). In the period 1981 to 1986 only seven deaths occurred due to asbestosis compared with 52 mesotheliomas, and this indicates a decline in the number with, or at least the severity of, asbestosis. Thus the predictions above may be too high, or the 160 to 200 as yet undiagnosed may be less severe forms of asbestosis.

Because four of the 41 deaths due to asbestosis have occurred in subjects not diagnosed in life, then a lower limit to the number of undiagnosed cases is 35 ( $10 \%$ of the 356 diagnosed cases). This estimate would be too low because the fact that asbestosis has been diagnosed in life increases the chance that it is recorded as the cause of death. A more prudent lower limit would perhaps be double this figure, 70 , to give a range of between 70 and 200 cases.

The above estimates are of the number of existing but undiagnosed cases. The question arises as to whether there could be onset of new cases in former workers who, if medically examined now, would be assessed as not having asbestosis. A study of the natural history of asbestosis in former workers at Wittenoom ${ }^{19}$ indicated that progression of asbestosis continues for many years after exposure has ceased. As the onset of asbestosis may be considered as a step in a progression starting with sub-clinical stages of the disease, it is reasonable to suppose that onset could also occur many years after exposure has ceased. It was also shown that the rate of progression of radiological abnormality was less for those who took longer to reach the first detectable stage. ${ }^{19}$ Thus if any new cases of asbestosis are yet to occur 20 years after exposure ceased, such cases would be expected to progress slowly and thus would be less likely to reach a stage at which a claim could be sustained. Walker $e t a l^{8}$ suggested that few new cases would occur 10 years after cessation of exposure.

A worst possible case is obtained from a figure in the paper by Cookson et al ${ }^{19}$ showing the time course to radiological abnormality. From this figure, and taking account of the time of employment of the Wittenoom group, it can be calculated that by 1987 at least $90 \%$ of the eventual yield of radiological abnormality would already have occurred. Although radiological abnormality is not sufficient to give a diagnosis of asbestosis, if it is assumed that $90 \%$ of the eventual number with asbestosis already have the disease, another 60 could develop the first detectable signs in the future. As discussed earlier these 60 would progress slowly.

COMPARISON WITH THE FINDINGS OF DE KLERK et $a l^{3}$ In comparing the results reported here with those of de Klerk et ll $^{3}$ one difference is that in my paper the predictions are of deaths due to mesothelioma and lung cancer, whereas de Klerk et $a^{3}$ predicted incidence of diagnosis. For these two types of malignancy, which usually prove fatal fairly rapidly, the differences between the two approaches would not be large. A second difference is that de Klerk et $a l^{3}$ truncated the predictions at age 85 ; in comparing the predictions a similar restriction will be applied to the results in this paper.

The most striking difference between the two predictions is in the total number of deaths, 2898 in men and women predicted by de Klerk et $a l^{3}$ compared with 3850 in men in this paper (there would have been another 170 deaths in women). This discrepancy is probably due to undetected deaths. de Klerk et $\mathrm{l}^{3}$ claimed that the effect of loss to follow up should only be slight on the basis that only a few cases of asbestos related disease are likely to have been missed. Their claim also depends on an accurate assessment of the population at risk and the future mortality from all causes. If some have died of causes unrelated to exposure to asbestos unknown to the authors then the number of survivors on 1 January 1987, the starting date of their prediction, will not be as high as they have assumed. More importantly, the survival of the population in the future will have been overestimated, as de Klerk et al $^{3}$ based their prediction on the observed mortalities and did not use State figures, and hence the number at risk of asbestos related disease will also have been overestimated.

de Klerk et $\mathrm{al}^{3}$ based their mesothelioma predictions on a relation of the same form as used in this paper with lag zero and the power was estimated as 
3.35. This gave 692 mesotheliomas compared with 624 in this paper. The predictions are reasonably close although the predicted proportion of mesotheliomas to total deaths $(692 / 2898=24 \%)$ by de Klerk $e t \mathrm{al}^{3}$ is higher. The confidence interval of de Klerk et $\mathrm{al}^{3}$ (394 to 990) was also similar to that in this paper for a lag of zero (394 to 960), although as discussed earlier this interval is too wide because it ignores information from other studies. The model used by de Klerk et $a l^{3}$ corresponds to the model giving the highest predictions and alternative forms were not considered.

de Klerk $e t a l^{3}$ predicted only 183 cases of lung cancer in 2898 deaths, a proportion of only $6.3 \%$, compared with 434 out of $3867(11 \cdot 2 \%)$. The current rates of death indicate that in Australia as a whole $8.4 \%$ of deaths in men in 1986 were due to lung cancer. ${ }^{20}$ Thus it is surprising that in a group with an increased risk due to exposure to asbestos only $6.3 \%$ would be predicted to die of this cause. The eventual proportion of lung cancers may well be less than that indicated on current figures because of declining rates of smoking in men. The difference between the two sets of predictions may be due to undetected deaths, but could also be due to a decline in excess risk after about 20 years since exposure, which would be taken account of by the method of de Klerk et al ${ }^{3}$; Walker ${ }^{21}$ concluded that excess risk declined after an interval since exposure ceased.

For asbestosis de Klerk et $a l^{3}$ predicted 482 more cases compared with a maximum of 260 in this paper. The two approaches were different and prediction of the number of cases of asbestosis is complicated by the delays that occur between onset and diagnosis, for reasons unrelated to the natural history of the disease, which place any attempt to fit a time dependent model to the observed time series at the mercy of non-random perturbations. Many, probably most, of those who may make a successful claim in the future already have asbestosis in an undiagnosed form. Such cases are developing the disease slowly as the mine has been closed for over 20 years and, as shown in an earlier paper on the Wittenoom group,,$^{19}$ the rate of progression of such cases after initial detection is also likely to be slow. Therefore, although considerable doubts accrue on the final number of cases, it may be stated more confidently that future claimants will be less disabled than those who have already made a successful claim. About $25 \%$ of those with asbestosis eventually die of the disease, another $25 \%$ of mesothelioma or lung cancer, and about $50 \%$ of unrelated causes.

Despite the differences in the predictions between those of de Klerk et $a l^{3}$ and those of this paper, and even using the lowest predicted number of mesotheliomas in this paper, the major continuing toll of the Wittenoom crocidolite mine will be deaths due to mesothelioma.

I am grateful to Professor M S T Hobbs for his permission to have access to the data and to Dr N H de Klerk for providing a copy of the data in computer readable form on disc. The Western Australian death rates and some extra data on asbestosis were also kindly supplied to me by Dr de Klerk. The paper is based on a report prepared for Australian Occupational Health Management Pty Limited, and I am grateful to Dr David Douglas for his support and encouragement. I am also grateful to $\mathrm{Mr}$ Neil Donnelly who carried out the computing of the mortality analysis.

1 Hobbs MST, Woodward SD, Murphy B, Musk AW, Elder JE. The incidence of pneumoconiosis, mesothelioma and other respiratory cancer in men engaged in mining and milling crocidolite in Western Australia. In: Wagner JC, ed. Biological effects of mineral fibres. Lyon: International Agency for Research on Cancer, 1980:615-25. (IARC Scientific publ No 30.)

2 Armstrong BK, de Klerk NH, Musk AW, Hobbs MST. Mortality in miners and millers of crocidolite in Western Australia. Br J Ind Med 1988;45:5-13.

3 de Klerk NH, Armstrong BK, Musk AW, Hobbs MST. Predictions of future cases of asbestos-related disease among former miners and millers of crocidolite in Western Australia. Med J Aust 1989;151:616-20.

4 Rogers A. Cancer mortality and exposure to crocidolite (letter). Br J Ind Med 1990;47:286-8.

5 Doll $R$. The causes of death among gas-workers with special reference to cancer of the lung. Br J Ind Med 1952;9:180-5.

6 Berry G. The analysis of mortality by the subject-years method. Biometrics 1983;39:173-84.

7 Coleman M, Douglas A, Hermon C, Peto J. Cohort study analysis with a FORTRAN computer program. Int $J$ Epidemiol 1986;15:134-7.

8 Walker AM, Loughlin JE, Friedlander ER, Rothman KJ, Dreyer NA. Projections of asbestos-related disease 19802009. J Occup Med 1983;25:409-25.

9 Cookson WOC, Musk AW, Glancy JJ, de Klerk NH, Yin R, Mele $\mathrm{R}$, et al. Compensation, radiographic changes, and survival in applicants for asbestosis compensation. $\mathrm{Br} J$ Ind Med 1985;42:461-8.

10 Peto J, Seidman H, Selikoff IJ. Mesothelioma mortality in asbestos workers: implications for models of carcinogenesis and risk assessment. Br J Cancer 1982;45:124-35.

11 Sullivan KR, Lam TH, Rossiter CE. HM naval bases: mesothelioma and time since first employment. Ann Occup Hyg 1988;32(suppl):491-6.

12 Thomas DC. Models for exposure-time-response relationships with applications to cancer epidemiology. Ann Rev Public Health 1988;9:451-82.

13 Seidman H, Selikoff IJ, Gelb SK. Mortality experience of amosite asbestos factory workers: dose-response relationships 5 to 40 years after onset of short-term work exposure. Am J Ind Med 1986;10:479-514.

14 Newhouse ML, Berry G, Wagner JC. Mortality of factory workers in east London 1933-80. Br J Ind Med 1985;42:4-11.

15 Newhouse ML, Berry G. Predictions of mortality from mesothelial tumours in asbestos factory workers. $\mathrm{Br} J$ Ind Med 1976;33:147-51.

16 Nicholson WJ, Perkel G, Selikoff IJ. Occupational exposure to asbestos: population at risk and projected mortality-19802030. Am J Ind Med 1982;3:259-311.

17 Wagner JC, Berry G, Skidmore JW, Timbrell V. The effects of the inhalation of asbestos in rats. Br J Cancer 1974;29:252-69.

18 Berry G, Rogers AJ, Pooley FD. Mesotheliomas-asbestos exposure and lung burden. In: Bignon J, Peto J, Saracci R, eds. Non-occupational exposure to mineral fibres. Lyon: International Agency for Research on Cancer, 1989:486-96. (IARC sci publ No 90.)

19 Cookson W, de Klerk NH, Musk AW, Glancy JJ, Armstrong B, Hobbs $M$. The natural history of asbestosis in former crocidolite workers of Wittenoom gorge. Am Rev Respir Dis 1986;133:994-8.

20 Australian Bureau of Statistics. Causes of death Australia 1986. Canberra: ABS, 1988.

21 Walker AM. Declining relative risks for lung cancer after cessation of asbestos exposure. J Occup Med 1984;26:422-6.

Accepted 8 May 1991 